This item was submitted to Loughborough's Research Repository by the author.

Items in Figshare are protected by copyright, with all rights reserved, unless otherwise indicated.

\title{
Determination of clothing microclimate volume
}

PLEASE CITE THE PUBLISHED VERSION

PUBLISHER

(C) Elsevier

VERSION

AM (Accepted Manuscript)

LICENCE

CC BY-NC-ND 4.0

REPOSITORY RECORD

Daanen, Hein A.M., Kent Hatcher, and George Havenith. 2019. "Determination of Clothing Microclimate Volume". figshare. https://hdl.handle.net/2134/14007. 
This item was submitted to Loughborough's Institutional Repository (https://dspace.lboro.ac.uk/) by the author and is made available under the following Creative Commons Licence conditions.

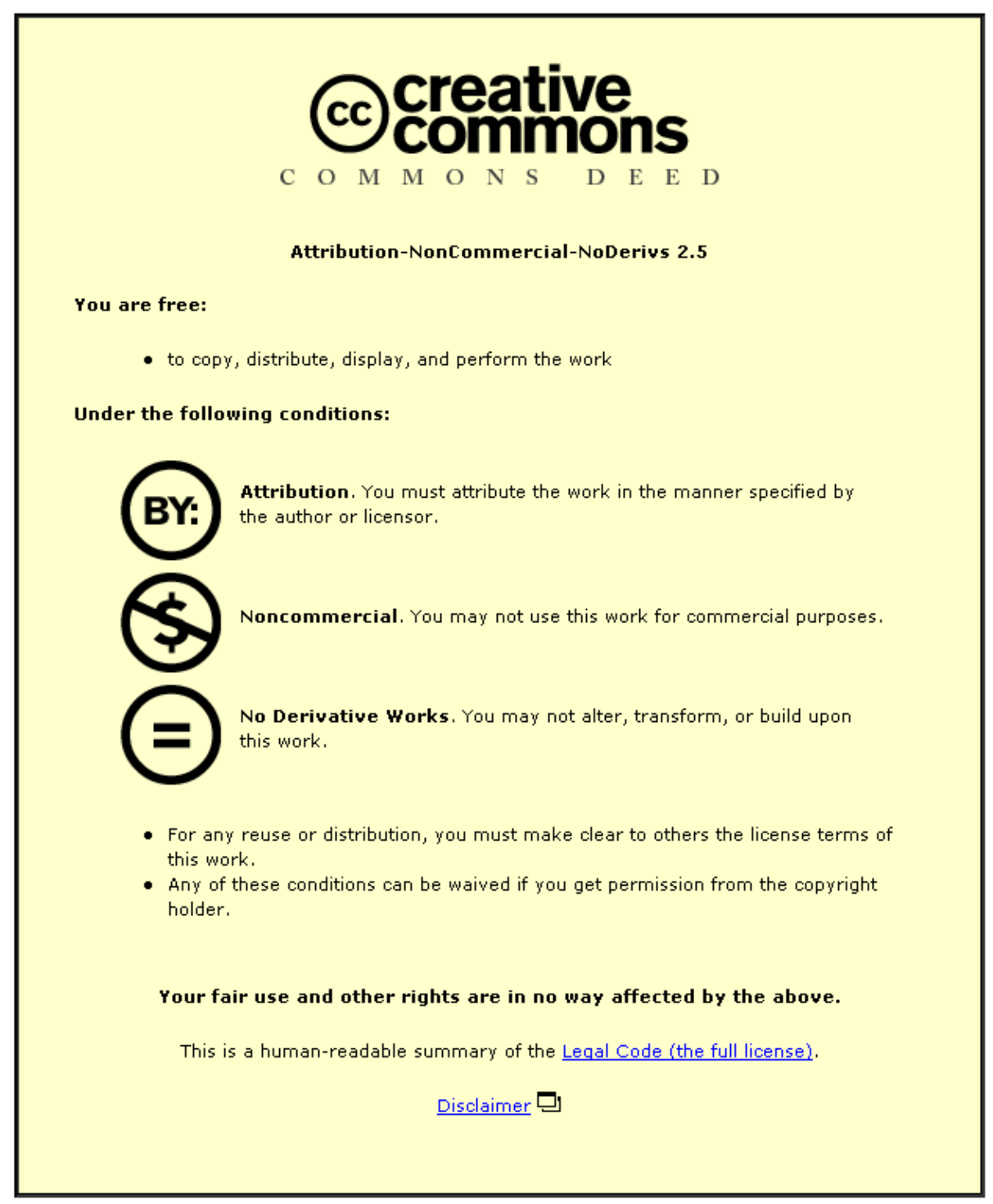

For the full text of this licence, please go to: http://creativecommons.org/licenses/by-nc-nd/2.5/ 


\title{
DETERMINATION OF CLOTHING MICROCLIMATE VOLUME
}

\author{
Hein Daanen ${ }^{1)}$, Kent Hatcher ${ }^{2)}$ and George Havenith ${ }^{2)}$ \\ 1) Thermal Physiology Group, Department of Work Environment, TNO Human Factors, The Netherlands \\ ${ }^{2)}$ Human Thermal Environments Laboratory, Dept. Human Sciences, Loughborough University, United Kingdom
}

\section{INTRODUCTION}

Human heat transfer depends on the amount of ventilation between the skin and the clothing layers, which in turn depends on the microclimate volume (7). This volume is hard to quantify. The traditional method, developed by Crockford et al. (4) and further in Birnbaum and Crockford (1) and Sullivan et al. (10) utilises a vacuum oversuit to evacuate and measure the quantity of air trapped in the microenvironment. This method is cumbersome and an alternative may be found in a model approach or using 3D whole body scans.

Lee and Hong (8) endeavoured to ascertain the relationship between the insulation value of the clothing ensemble and the air volume measured by using phase-shifting moiré topography. They determined the microclimate volume between a manikin and a T-shirt. This technique was time efficient and accurate, but it was not reported if this technique could be used on humans and how the results compared to the traditional technique of microclimate volume measurement.

A third technique to estimate the microclimate volume assumes that the body is represented by a series of cylinders. The circumference of each segment is measured with and without clothing, allowing the volume of each to be calculated. The method was adopted from Lotens and Havenith (9) and is fast and simple.

It is the purpose of this study to compare the reliability and reproducibility of the vacuum suit method, scanning method and cylinder model to determine microclimate volume.

\section{METHODS}

Four healthy males were investigated in three conditions: seminude (only wearing bicycle shorts), wearing a T-shirt and wearing a coverall. Anthropometrical data on the subjects is supplied in Table 1. The T-shirt was size L for all subjects. The shirt was evaluated untucked from the bicycle shorts. The size of the coverall was determined by the chest circumference.

TABLE 1 Subject physical characteristics

\begin{tabular}{|c|c|c|c|}
\hline $\begin{array}{l}\text { Subject } \\
\text { Number }\end{array}$ & $\begin{array}{c}\text { Height } \\
\text { (cm) }\end{array}$ & $\begin{array}{c}\text { Weight } \\
\text { (kg) }\end{array}$ & Surface Area $\left(\mathrm{m}^{2}\right)(6)$ \\
\hline 1 & 187 & 78 & 2.03 \\
\hline 2 & 177 & 77 & 1.94 \\
\hline 3 & 180 & 70 & 1.89 \\
\hline 4 & 185 & 65 & 1.86 \\
\hline Mean & 182 & 73 & 1.93 \\
\hline $1 \mathrm{SD}$ & 4.6 & 6.1 & 0.07 \\
\hline
\end{tabular}

Scanner: The first method to determine microclimate volume was whole body scanning (5). The subjects were scanned in each condition using a Vitronic Vitus Pro scanner (www.vitronic.de) and Polyworks software (www.innovmetric.com) to determine the volume. The scanner uses 16 camera's to determine the shape of the subject and 4 camera's for the colour texture. The resolution of the scanner is approximately $3 \mathrm{~mm}$. The volume under the Tshirt or coverall was determined by subtracting the volume of the seminude body from the volume of the scan with Tshirt or coverall. Figure 1 shows a frontal and transversal view of the scans for a subject.

Vacuum suit: The second method used a thin airtight suit over the garments (2). Air was pumped out until the suit is crushed tight against the body. The removed air volume was measured from the moment the suit touched the garments until it was tight against the body. For this laboratory experiment, the subjects had an impermeable over suit of 0.015 $\mathrm{cm}$ thickness made from Tyvek, an air impermeable non-woven fabric. All the seams of the suit were stitched and taped. There is a large air tight zipper entry for the suit on the back. The suit was purchased from Remploy of Merseyside, UK. The neck seal was purchased from ML Lifeguard Equipment and fitted on the over suit by Remploy. Figure 2 shows the measurement set-up.

An air pump (Pfeiffer) was used to evacuate the air from the suit. A Schlumberger air flow meter, combined with a timer was used to measure the volume of air evacuated from the over suit. A Fluke 75 Series II Multimeter registered the electronic output of the U-tube manometer. 


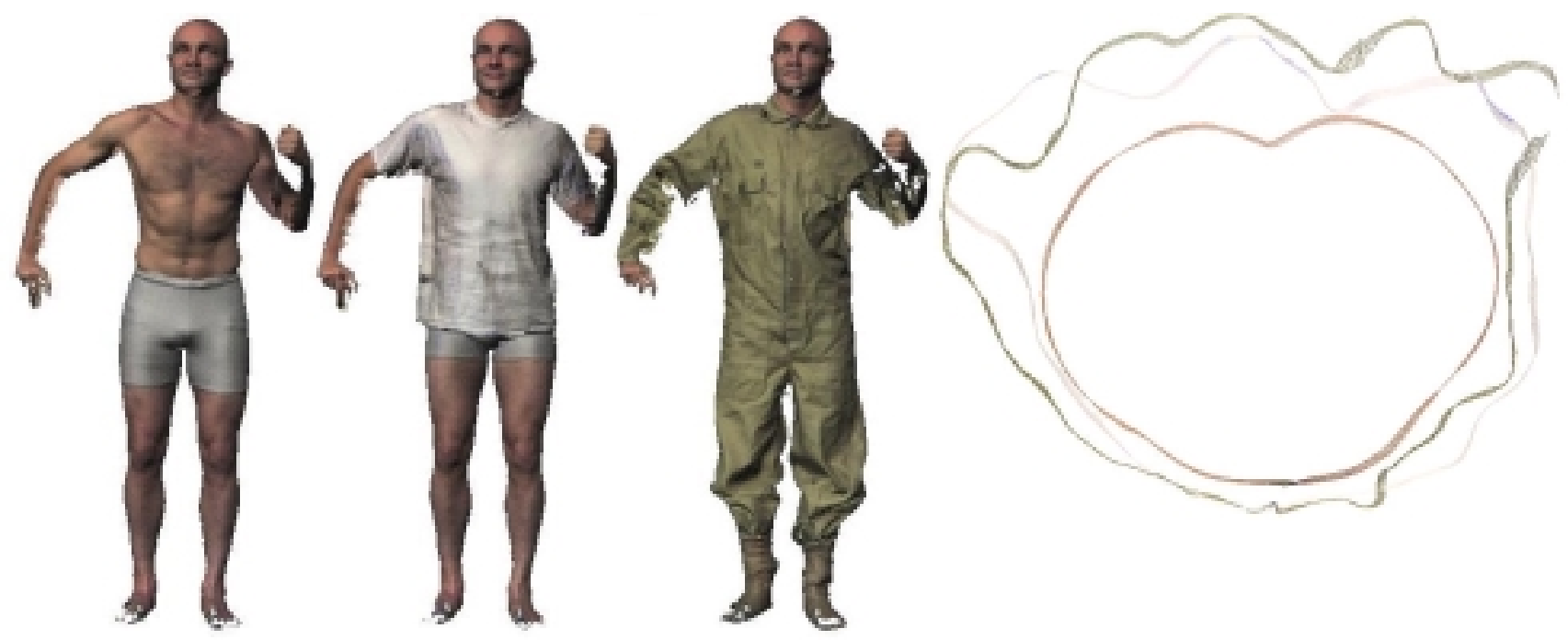

Fig. 1 Frontal and transversal view of the scans for subject 1 . The inner object is the torso, the thin line is the Tshirt and the thick line is the coverall. Please note that the folds are well covered by the scanner.

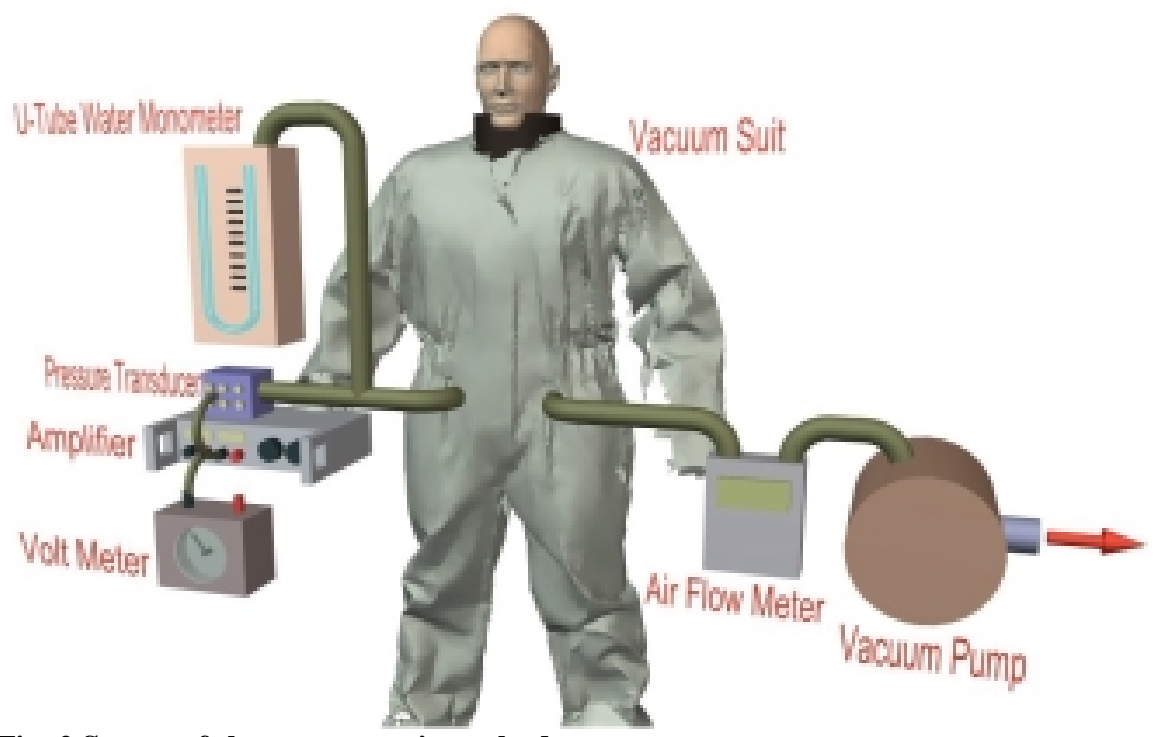

Fig. 2 Set-up of the vacuum suit method

The protocol used for this part of the project is based on Sullivan et al.'s (10) adaptation of the original Crockford method (4). On arrival the subjects changed into the semi-nude ensemble (the tight-fitting bicycle shorts). The tubing system was taped on to the subjects torso, arms and legs. The tubes were $9 \mathrm{~mm}$ in diameter with perforations every 5 $\mathrm{cm}$. Near the end of each tube, the amount of perforations increased.

The suit was sealed and the pump was turned on, evacuating the air. Recordings of both the pressure and the volume were made every 15 seconds, in order to best compare the results with data from the literature. The air from the enclosed environment was evacuated until an internal pressure of $-30 \mathrm{~cm} \mathrm{H}_{2} \mathrm{O}$ was reached, at which point the pump would be shut off. The beginning point for volume determination was chosen to be $-0.75 \mathrm{~cm} \mathrm{H}_{2} \mathrm{O}$. This beginning point was chosen because early trials suggested that below this pressure there was a consistent rate of decline, rather than a fluctuation between a positive and negative rate of pressure change. This differs from the $-0.90 \mathrm{~cm} \mathrm{H}_{2} \mathrm{O}$ used by Sullivan et al. (10), which they observed where the over suit was just short of being in full contact with the clothing ensemble. This will theoretically result in a slightly larger recorded microclimate volume.

Circumference model: The third method estimated the microclimate volume by measuring circumferences of the nude and clothed body, modelling the human body in cylinders (9). The difference in cylinder volumes between clothed and nude was taken as the microclimate volume. Circumference measures were taken three times at each of the 13 body segments, for each of the three clothing ensembles. An average was taken to be entered into the computer model (Cloman, 9) A schematic drawing of the cylinder model is provided in Figure 3. 
Each measurement was repeated three times, in order to compare the reproducibility of the method. Three scans were made in each ensemble consecutively. For the suit measurements the tubes were kept in place, but the suit was unzipped in between. The circumferences for the cylinder model were also determined three times.

\begin{tabular}{l|l} 
BODY SEGMENT & WHERE CIRCUMFERENCE MEASURE TAKEN \\
\hline 1 Head & The point of largest circumference \\
2 Face & Cloman default values used \\
3 Neck & At the level of C-7 \\
4 Shoulders & Around the acromion extremities under the arms, with loose arms \\
5 Upper trunk & Across both the scapulae and the nipples \\
6 Lower trunk & Between the lower ribs and the superior iliac crest \\
7 Upper arm & At the point of greatest circumference around the biceps group \\
8 Lower arm & Approximately 5 cm distal from the olecranon process \\
9 Hands & Cloman default values used \\
10 Thighs & At the point of greatest circumference \\
11 Upper calf & At the point of greatest circumference around the gastrocnemius \\
12 Lower calf & Approximately $10 \mathrm{~cm}$ proximal from the malleoli \\
13 Feet & Cloman default values used
\end{tabular}

Fig. 3 Model used to estimate the microclimate volume (9)

\section{RESULTS}

The microclimate volume of the T-shirt was $12 \pm 2,4 \pm 1$ and $13 \pm 4 \mathrm{dm}^{3}$ for the scanning method, model and suit method respectively (Fig. 4). The microclimate volume of the coverall was $33 \pm 5,27 \pm 5$ and $28 \pm 8 \mathrm{dm}^{3}$, respectively. The standard deviation mainly reflects differences between subjects.

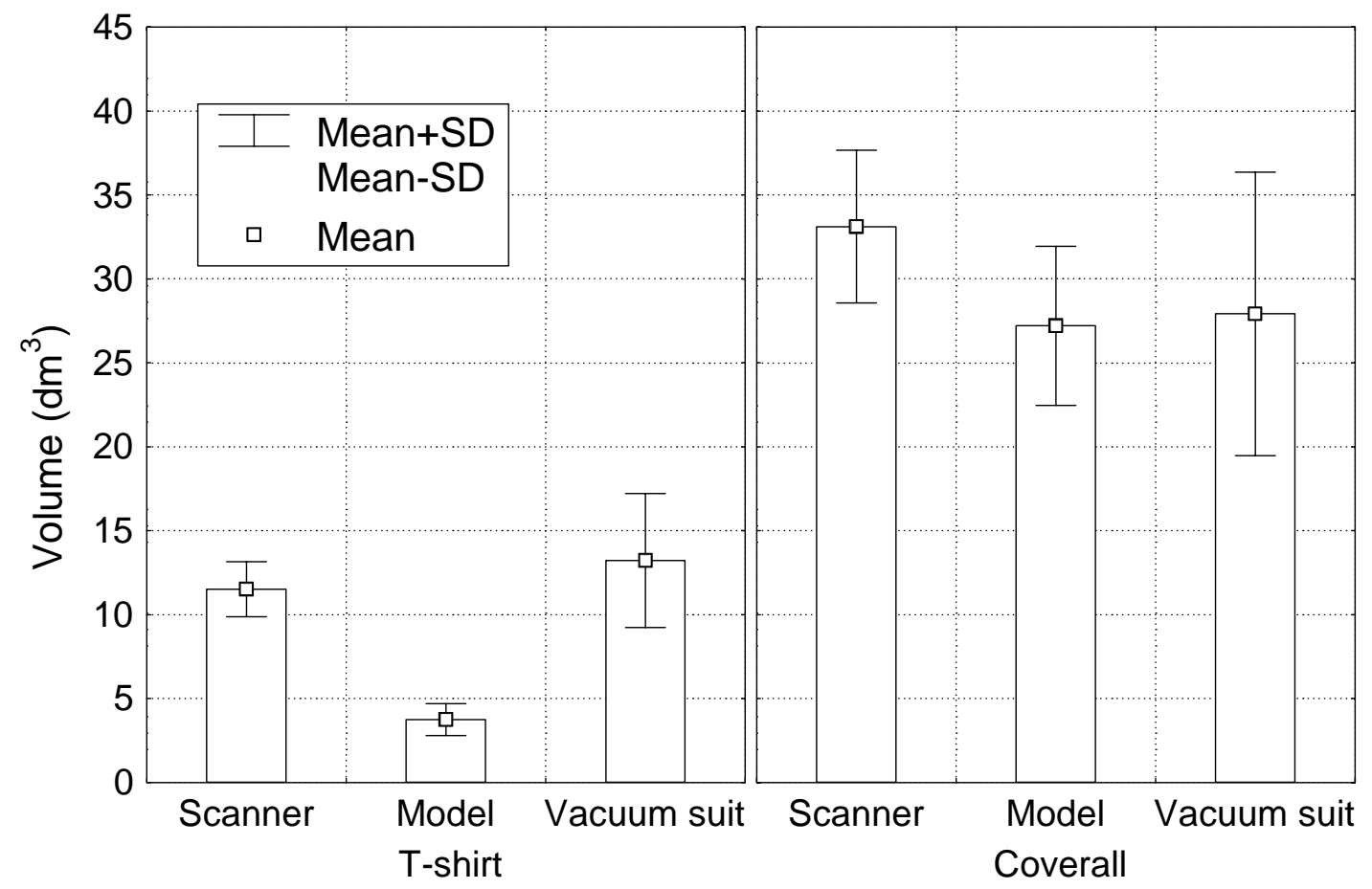

Fig. 4 Microclimate volume determined by scanning, cylinder model and vacuum suit.

The difference within subjects (three repetitions) was about $1 \%$ for the scanning method, $3 \%$ for the model and $8 \%$ for the suit. The error in the model is based on three averaged circumferences for the nude condition. If each individual measurement is taken, the error increases to $54 \%$. 


\section{DISCUSSION}

The results show that considerable differences exist in microclimate volume between the three investigated methods. The volume under the T-shirt is much less when estimated with the model. It is likely that the tape compresses the shirt too easily, which causes the underestimation. For the coverall, the model estimation is closer to the suit and scan methods.

The reproducibility is best for the scan method. A problem is that occlusion effects causes holes in the scans that have to be filled manually in order to be able to calculate volumes. Hole filling techniques are progressively improving, e.g. Carr et al. (3). The vacuum suit method is time consuming and error prone. The model may offer an easy estimation of clothing microclimate volume, but efforts should be undertaken to validate this model. Repeated circumference measures are necessary to reduce the errors.

It can be concluded that the microclimate volume determined by the $3 \mathrm{D}$ scanning method was most reproducible.

\section{ACKNOWLEGDGEMENTS}

The authors acknowledge Koen Tan and Martine Brandsma for the measurements, Emiel den Hartog and Wouter Lotens for the scientific assistance and Dalien Cable for the graphics. EPSRC is thanked for financial support to Mr. Hatcher (grant GR/N10509).

\section{REFERENCES}

1) Birnbaum, R.R., Crockford, G.W. 1978. Measurement of the clothing ventilation index, Applied Ergonomics 9 (4): 194-200

2) Bouskill L.M., Havenith, G., Kuklane, K., Parsons, K.C., Withey, W.R. 2002. Relationship between clothing ventilation and thermal insulation. American Industrial Hygiene Association Journal, in press

3) Carr, J.C., Beatson, R.K., Cherrie, J.B., Mitchell, T.J., Fright, W.R., McCallum, B.C., Evans, T.R. 2001. ACM SIGGRAPH 2001, Los Angeles, CA, pp67-76, 12-17 August 2001.

4) Crockford, G.W., Crowder, M., Prestidge, S.P. 1972. A trace gas technique for measuring clothing microclimate air exchange rates. British Journal of Industrial Medicine 29: 378-386

5) Daanen, H.A.M., Water, G. J. van de. 1998. Whole Body Scanners. Displays 19 (3): 111-120

6) DuBois, D., DuBois, E.F. 1916. A formula to estimate the appropriate surface area if height and weight are known, Archives of Internal Medicine 17: 863-871

7) Havenith, G., Heus, R., Lotens, W.A. 1990. Resultant clothing insulation: a function of body movement, posture, wind, clothing fit and ensemble thickness. Ergonomics 33 (1): 67-84

8) Lee, Y., Hong, K. 2000. Measurement of air volume in clothing microclimate and its relationship with thermal insulation. In: Proceedings of the 9th International Conference on Environmental Ergonomics. Dortmund, Germany July 30-August 4, 2000. Pages: 303-306

9) Lotens, W.A., Havenith, G. 1991. Calculation of clothing insulation and vapour resistance. Ergonomics 34 (2): 233-254

10) Sullivan, P.J., Mekjavic, I.B., Kakitsuba, N. 1987. Determination of clothing microclimate volume. Ergonomics 30 (7): 1043-1052 